\title{
MONSTROS FABULOSOS: DRÁCULA, ALICE, SUPER-HOMEM E OUTROS AMIGOS LITERÁRIOS (2019), DE ALBERTO MANGUEL
}

Flavio García (UERJ)

Flavio García é professor associado da UERJ; bolsista PROCIÊNCIA (UERJ-FAPERJ); orienta iniciação científica, mestrado e doutorado e supervisiona pós-doutorado. É pós-Doutor pela UFRJ (2008), pela UFRGS (2012) e pela Universidade de Coimbra (2016), e pós-Doutorando pela Universidade de Lisboa (2020-2022), com projetos de pesquisa sobre o insólito ficcional e/ou sobre a ficção de Mia Couto. Líder do grupo de pesquisa "Nós do Insólito: vertentes da ficção, da teoria e da crítica" junto ao Diretório de Grupos do CNPq; coordena o SePEL. UERJ (www.sepel.uer.br); é um dos editores do e-DDIF (www.insolitoficcional.uerj.br).

Lattes: http://lattes.cnpq.br/4242057381476599.

E-mail: flavgarc@gmail.com

ORCID iD: https://orcid.org/0000-0003-0761-8092 
Monstros fabulosos: Drácula, Alice, Super-homem e outros amigos literários, do argênteo-canadense Alberto Manguel, com ilustrações do próprio autor, publicado por Edições Tinta da China, Lisboa, Portugal, em 2019, é um livro provocante.

Manguel fala de diferentes personagens da literatura universal, desde a Antiguidade até a Contemporaneidade, percorrendo sua gênese, sobrevida e transmigrações interliterárias e intermidiáticas. Na página Agência Literária Barcelona, tem-se notícia da publicação do livro pelo mundo afora e em diferentes línguas, incluindo o que parece ter sido sua matriz, Monsieur Bovary (y otros amigos tenaces), publicado em 2018. A despeito da excelente escrita do autor, dedicado à

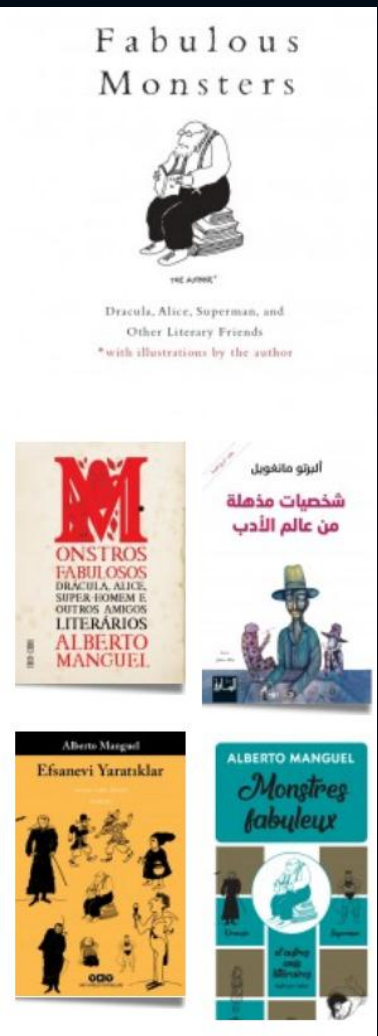
leitura e à formação de leitores, a versão portuguesa, cuja tradução se deve à Rita Almeida Simões, é fabulosamente agradável de ler.

Manguel tem sua primeira publicação no Brasil em 1977 com Uma história da leitura pela Companhia das Letras. Até 2020, ele conta com quinze livros publicados por essa mesma editora, dos quais, tendo em vista a política editorial da Revista Abusões, merecem destaque Contos de horror do Século XIX (2005) e Dicionário de lugares imaginários (2003), este último escrito em coautoria com Gianni Guadalupi. 
Em 2020, a Tinta da China está publicando a edição portuguesa de Com Borges, reconhecido como "um livro-homenagem que é também a memória afectiva do encontro entre dois génios", cuja edição original data de 2004.

Manguel era um rapazola de 16 anos, trabalhando na livraria Pygmalion, em Buenos Aires, na Argentina, quando conheceu Jorge Luís Borges que, percebendo o entusiasmo do jovem, convidou-o para trabalhar como "seus olhos". Borges já estava praticamente cego de todo e mantinha sempre alguém que pudesse ler para si. O livreiro aceitou. Conviveram por 4 anos. Os resultados podem-se perceber na obra de Manguel.

A resenha implica um texto que apresente postura crítica, olhar distanciado, exame e análise, isenção avaliativa, descrição da obra resenhada, atribuindo-Ihe critérios de valor e oferecendo um conjunto sistemático de informações que promovam interesse ou não por sua leitura. A edição portuguesa de Monstros fabulosos impõe-se ao resenhista de modo traiçoeiro, não lhe permitindo a crítica distanciada e isenta, embotando-Ihe o exame e a análise, interferindo na composição do quadro de informações a ser oferecido e, consequentemente, acabando por alterar a provocação para sua leitura. Seu resenhista acaba por ser um traidor.

Sua capa, comparada com as demais que se podem ver na Agência Literária Barcelona, é, incontestavelmente, a menos atraente de todas, nas quais destacam-se imagens de algumas das personagens monstruosamente fabulosas de que trata Manguel. Sua ilustração, presente na dedicatória e nas páginas de abertura de cada capítulo, assemelha-se a rabiscos despretensiosos de 
jovens entediados durante uma aula ou de executivos enfadados em meio a reuniões de trabalho.

Sua dedicatória, que parece se dirigir às filhas, compõe-se, em primeiro plano, da imagem de uma menina maior, com vestido de barra rodada e coroa na cabeça, e, em segundo plano, de uma menina bastante menor, por detrás daquela, vestida com o que faz lembrar um pijama de peça única, segurando uma espécie de dragãozinho. Acima da ilustração da dedicatória, lê-se: "Para a Amélia, que gosta de princesas, e a Olívia, que prefere dragões”. Assim, a dedicatória prenuncia o conteúdo o livro: personagens maravilhosas, encantadas, mágicas e monstruosas.

O "Prefácio" e, consequentemente, o livro abrem-se com uma epígrafe buscada em Alice do outro lado do espelho, de Lewis Carroll. Trata-se do fragmento em que Alice é apresentada por Felge ao Unicórnio como sendo coisa séria e muito verídica. O Unicórnio diz a Felge que sempre pensou que as meninas fossem monstros fabulosos. Em contraponto, Alice diz que também pensava que os unicórnios fossem monstros fabulosos, nunca tinha visto um vivo. Naquela situação, entretanto, Unicórnio e Alice, frente a frente, têm-se, então, por realidade. Desta forma, o Unicórnio propõe a Alice que acredite nele, pois, assim, ele também acreditaria nela. Com esta epígrafe, estabelecem-se as regras do jogo discursivo, definindo-se, em um só lance, autor e leitor-modelo.

O texto de Manguel transita entre o ensaio acadêmico, o artigo de opinião e a ficção, sempre muito próximo à (con)fusão genológica desses tempos pós-pós-modernos adentrados no século XXI. Apresentadas as possíveis matrizes genéticas das 
personagens, os capítulos voltam-se para sua composição e sobrevida, imiscuindo figuras históricas - seres de carne e osso - e ficcionais - seres de papel -, que permutam mundos de existência - fatual e ficcional.

Desse modo, a perspectiva de Manguel aproxima-se da de Umberto Eco em seus Seis passeios pelos bosques da ficção, em especial quando assevera que "[a] biologia diz-nos que descendemos de criaturas de carne e osso, mas, no fundo, sabemos que somos filhos e filhas de fantasmas de papel e tinta".

Sem apresentar as fontes do que diz, porque, ao que parece, isso pouco lhe importa, o autor apresenta a origem da palavra "ficção", que teria entrado na língua portuguesa - a referência é feita à entrada na língua portuguesa - no início do Século XVI, a partir da língua francesa, em derivação do particípio passado do verbo latino fingere, significando "suposição", "hipótese", que, na origem, teria significado "modelar na argila, criar".

A partir dessas observações, ele conclui que "[a] ficção é, portanto, uma espécie de Adão verbal, moldado à imagem do Autor", e chega a supor que, "[t]alvez por isso, e apesar da contradição, as melhores personagens de ficção tantas vezes nos parecem mais vivas do que amigos de carne e osso". Dessa forma, ele equipara Deus e Autor, pondo-os num mesmo patamar e, em certa medida, retoma a concepção clássica de que a arte seria produto da inspiração divina. Contudo, subverte a relação de causa e efeito, produto e produtor, amalgamando criador e criatura.

Manguel lembra que "Rei Lear e Lady Macbeth, Dom Quixote e Dulcineia são presenças reais mesmo para muitas pessoas 
que nunca leram os livros", e essa lembrança permite outra aproximação com os Seis passeios de Eco. O semiólogo italiano observou o quanto Napoleão poderia soar ficcional. O escritor argênteo-canadense observa ainda que "[o]s leitores sempre souberam que os sonhos da ficção engendram o mundo a que chamamos real", e o italiano já havia comentado que a ficção costuma ser mais confortável e, às vezes, muito mais real para os leitores.

Para justificar a seleção dos monstros fabulosos que habitam seu livro, Manguel adverte que "[n]em todas as personagens literárias são companheiros de eleição de todos os leitores; só aquelas de que mais gostamos nos seguem ao longo dos anos". Segue explicando que "[t]alvez um dos principais atractivos destes monstros fabulosos sejam as suas múltiplas e mutáveis identidades".

Essas personagens de que fala, "são impossíveis de prender entre as capas dos seus livros, por breve ou vasto que esse espaço seja", elas ganham vida própria, evadem-se da ficção, adentram a realidade quotidiana. "Ao contrário dos seus leitores, que envelhecem e nunca voltam a ser jovens, as personagens ficcionais são, ao mesmo tempo, quem eram quando lemos as suas histórias pela primeira vez e quem se tornam no decurso das nossas sucessivas leituras".

Ancorando ficção na realidade e realidade na ficção, num jogo cíclico e circular entre os mundos objetivo e ficcional, sem perder de vista a atualidade de seu texto, Manguel discorre sobre episódios que acontecem proximamente ao seu tempo de escrita. Segundo ele, "[n]esta nossa era de angústia, as migrações forçadas, os 
refugiados persistentemente optimistas, as pessoas que procuram asilo e naufragam e dão à costa na Europa reflectem-se todos na figura de Ulisses a tentar chegar a casa".

Esgarçando sua perspectiva, o mesmo raciocínio se poderia estender àqueles que tentaram e ainda tentam chegar aos Estados Unidos, fosse por via marítima, como muitos cubanos tentaram por décadas seguidas, seja por via terrestre, como latino-americanos fazem constante e insistentemente a partir do México. Poder-se-ia, ainda, avançando em direção a extremos, abarcar casos pontuais dos que morrem em porões ou trens de pouso de aviões na tentativa de migrar.

São 38 capítulos cujos títulos são identificados pelo nome de uma ou mais de suas personagens monstruosamente fabulosas. Todavia, Manguel não se limita à abordagem desses monstros fabulosos que emprestam algum aspecto de sua figuração ao título dos capítulos. Na maioria das vezes, ele perpassa um entorno de personagens que, em diferentes textos literários e em variados media, coabitam o mesmo espaço ficcional dessas figuras.

Provocativamente, vão-se manter aqui os nomes das personagens na tradição portuguesa ou, que seja, na escolha do autor, esperando, com isso, estimular a leitura do livro e a pesquisa de suas fontes.

A indicação das fontes, como se alerta no livro, nem sempre correspondeu à versão na língua original, tendo o autor trabalhado sobre traduções feitas por ele mesmo ou com as que tenha reconhecido confiáveis. O mesmo procedimento parece ter sido adotado pela tradutora. 
Seguem, então, os títulos dos capítulos e as fontes indicadas por Manguel, demonstrando a multiplicidade tipológica das personagens abordadas, a diversidade das fontes a que recorreu, a variedade midiática em que verificou a presença das personagens, com passagens por diferentes tempos históricos, espaços geográficos, línguas nacionais e, mesmo, perspectivas artísticas e teórico-ensaísticas:

1. "Monsieur Bovary" - Madame Bovary de Gustave Flaubert;

2. "Capuchinho Vermelho" - dos Irmãos Grimm;

3. "Drácula" - Drácula de Bram Stoker;

4. "Alice" - Alice no país das maravilhas e Alice do outro lado do espelho de Lewis Carroll;

5. "Fausto" - The Tragical History of the Life and Death of Doctor Faustus de Christropher Marlowe e Fausto de Johann Wolfgang von Goethe;

6. "Gertrudes" - Hamlet de William Shakespeare;

7. "Super-Homem" - Superman (banda desenhada da DC Comics) de Jerry Siegel e Joe Shuster, Man and Superman de George Bernard Shaw, "How I Found the Superman" (em Alarms and Discursions) de G. K. Chesterton e Also Sprach Zarathustra e Ecce Homo: Wie man wird, was man ist de Friedrich Nietzsche;

8. "Don Juan" - Don Juan, ou Le festin de pierre de Molière, II dissoluto punito, ossia il Don Giovanni de Wolfgang Amadeus Mozart e Lorenzo Da Ponte, El burlador de Sevilla o el convidado de piedra de Tirso de Molina, Don Juan de George Gordon e Lord Byron e Don Juan Tenorio de José Zorrilla; 
9. "Lilith" - The Book of Legends: Seffer Ha-Aggabad, Legends from the Talmud and Midrash editado por Hayyin Nahman Bialik e Yehoshua Hana Ravnitzky e The Talmud: A Selection editado por Norman Solomon;

10. "O Judeu Errante" - Kurze Beschreibung und Erzählung von eiem Juden mit Namen Ahasverus, Le Juif errant de Eugène Sue, L'amante senza fissa demora de Carlo Fruttero e Franco Lucentini e "El Inmortal" (em El Aleph) de Jorge Luís Borges;

11. "Bela Adormecida" - "La Belle au bois dormant" de Charles Perrault e "A rosa espinosa" dos Irmãos Grimm;

12. "Phoebe" - The Catcher in the Rye de J. D. Salinger;

13. "Hsing-chen" - The Nine Cloud Dream de Kim Man-Jung;

14. "Jim" - Adventures of Huckleberry Finn de Mark Twain;

15. "Quimera" - A llíada de Homero, Teogonia e Trabalhos e Dias de Hesíodo e The Greek Myths de Robert Craves;

16. "Robinson Crusoe" - The Lyfe and Strange Surprizing Adventures of Robinson Crusoe, of York, Mariner de Daniel Defoe;

17. "Queequeg" - Moby Dick; or The Whale de Herman Melville;

18. "Tirano Banderas" - Tyrant Banderas de Ramón del Valle-Inclán;

19. "Cide Hamete Benengeli" - Dom Quixote de la Mancha: o engenhoso fidalgo de Miguel de Cervantes;

20. “Job" - Bíblia e Guide of the Perplexed de Moisés Maimónides;

21. "Quasimodo" - Notre-Dame de Paris de Victor Hugo;

22. "Casaubon" - Middlemarch: A Study of Providencial Life de George Eliot;

23. "Satanás" - Livro dos Judeus (Livros Apócrifos), Divina Comédia de Dante Alighieri, Paraíso Perdido de John Milton, 
Satan's Tragedy and Redemption: Iblis in Psychology de Peter J. Awn, The Rise and Fall of Adam and Eve: The Story That Created Us de Stephen Greenblatt, Faust de Johan Wolfgang von Goethe;

24. "Hipogrifo" - Orlando Furioso de Ludovico Ariosto;

25. "Capitão Nemo" - Vingt mille lieues sous les mers e L'ile mystérieuse de Júlio Verne;

26. "Monstro de Frankenstein" - Frankestein; or The Modern Prometheus de Mary Shelley e Frankenstein (Universal Studios, 1931);

27. "Arenoso" - Monkey: Folk Novel of China de Wu Cheng'en;

28. "Jonas" - Bíblia;

29. "Emília" - A Menina do Narizinho Arrebitado, O Picapau Amarelo e Serões de Dona Benta de Monteiro Lobato;

30. "Wendigo" - Wendigo: An Anthology of Fact and Fantastic Fiction, editado por John Robert Colombo;

31. "Avô da Heidi" - Heidi de Johana Spyri;

32. "Elisa Esperta" - "A Elsa esperta" dos Irmãos Grimm;

33. "Long John Silver" - Treasure Island de Robert Louis Stevenson;

34. "Karagöz e Hacivat" - Selected Stories of Hacivat and Karagöz, editado por Seynep Üstü;

35. "Émile" - Émile, ou De l'éducation de Jean-Jacques Rousseau;

36. "Simbad" - Les Mille et une nuits: Contes árabes;

37. "Mandarim" - O Mandarim de Eça de Queirós;

38. "Wakefield" - "Wakefield" em Twice-Told Tales de Nathaniel Hawthorne. 
Esse quadro é demasiado provocativo e, à semelhança d'O livro dos seres imaginários de Borges, deixa o resenhista, sendo ele de base acadêmica, inseguro diante de seu texto, pois se sente atraído pelo ensaio em lugar da recensão. Entretanto, atento, limita-se ao essencial.

Em linhas bem gerais, admitindo-se que muito vá ficar de fora da tentativa de agrupamento e, mesmo agrupado, incorra em erro de percepção, podem-se reunir, pensando ainda nos interesses editoriais da Revista Abusões, "Capuchinho Vermelho", "Alice”, "Bela Adormecida", "Emília", "Avô da Heidi" e "Elisa Esperta" no conjunto de personagens da literatura para crianças; "Drácula", "Fausto", "Satanás", "Monstro de Frankenstein" e "Wendigo" no universo do que pode mais notadamente perceber como gótico ou fantástico; "Super-Homem", na ficção científica; os demais, com muito pouca exceção, transitariam por diferentes vertentes ficcionais do insólito.

A sedução pelo avanço teórico, metodológico e crítico sobre esses monstros fabulosos, a partir do que Alberto Manguel apresenta, é quase irresistível, mas o gênero textual resenha impõe que se limite. Assim, dá a obra por recenseada, esperando-se que outros leitores se deixem enlear irresistivelmente. 